\title{
Virtual experience, real consequences: the potential negative emotional consequences of virtual reality gameplay
}

\author{
Raymond Lavoie $^{1} \cdot$ Kelley Main ${ }^{1} \cdot$ Corey King ${ }^{2} \cdot$ Danielle King $^{2}$
}

Received: 29 July 2019 / Accepted: 20 March 2020 / Published online: 2 April 2020

(c) The Author(s) 2020

\begin{abstract}
As virtual reality (VR) technology enters mainstream markets, it is imperative that we understand its potential impacts on users, both positive and negative. In the present paper, we build on the extant literature's focus on the physical side effects of VR gameplay (e.g., cybersickness) by focusing on VR's potential to intensify users' experiences of negative emotions. We first conducted a preliminary survey to assess users' emotional responses during VR gameplay, with the results suggesting that certain VR situations can in fact produce intense negative emotional experiences. We then designed an interactive scenario intended to elicit low to moderate amounts of negative emotion, wherein participants played out the scenario in either VR (using the HTC Vive) or on a laptop computer. Compared to the participants who enacted the scenario on the laptop, those in the VR condition reported higher levels of absorption, which in turn increased the intensity of their negative emotional response to the scenario. A follow-up questionnaire administered several hours later revealed that the intensified negative emotions resulting from VR had a significant positive correlation with negative rumination (i.e., harmful self-related thoughts related to distress). These results show that VR gameplay has the potential to elicit strong negative emotional responses that could be harmful for users if not managed properly. We discuss the practical and policy implications of our findings.
\end{abstract}

\section{Introduction}

Virtual reality (VR) is a human-computer interface that provides users with various physical sensations (e.g., visual, haptic, auditory) to increase realism in the virtual world (Seth et al. 2011). This heightened sense of realism produces a phenomenon known as "presence," which refers to the user's authentic experience of being in the virtual world as a result of visual or auditory displays generated by a computer (Sheridan 1992; Barfield and Hendrix 1995). VR's ability to provide users with highly realistic immersive experiences asserts it as a powerful tool that can potentially allow for the creation of novel consumption experiences (De Gauquier et al. 2018; Lau and Lee 2018).

As VR technology becomes more mainstream, it is important to understand its potential impacts on users, both positive and negative (Lavoie and King 2019). While the majority of research has focused on the positive effects of VR (e.g.,

Raymond Lavoie

lavoier@merrimack.edu

University of Manitoba, Winnipeg, MB, Canada

2 Zenfri Inc., Winnipeg, MB, Canada
Cardoş et al. 2017), we contend that it is equally critical to examine potential negative outcomes as well. Specifically, we suggest that it is important both to understand and actively work to mitigate any negative consequences associated with VR usage. Based on a review of the literature, preliminary conversations with VR developers, and research from within the academic community, it is evident that VR use can result in negative physiological outcomes, such as nausea or dizziness (Regan 1995; Akiduki et al. 2003) and eye fatigue (Cao et al. 2019). However, there appears to be limited evidence regarding any other negative consequences related to VR.

Our research builds on prior studies demonstrating VR's ability to influence emotions (Plante et al. 2003) by using survey and experimental methodologies to empirically explore VR's potential to elicit negative emotional responses, particularly in relation to VR video games. Our findings identify a key ethical concern, namely, that VR gameplay may potentially have harmful emotional consequences for users, depending on the nature of the content.

First, we conducted a survey of people's previous experiences with VR in order to obtain preliminary evidence of any resulting intensified negative emotional outcomes. The survey results revealed that certain virtual reality content (i.e., frightening characters) did lead to strong, persistent 
negative emotions. While the survey results indicated that VR experiences can produce strong negative emotions, it is also true that other mediums can do so as well. Therefore, in Study 2 we directly compared the relative strength of negative emotions elicited by the same video game content in both $2 \mathrm{D}$ and VR. To do so, we partnered with a video game developer to create a game that would elicit low to moderate levels of negative emotion and that could be played in both VR and on a laptop.

The results of Study 2 revealed that the participants who had played the video game in VR experienced stronger negative emotions afterward compared to those who had played it in 2D on the laptop. In particular, VR enhanced the level of absorption into the scenario, which mediated an increase in the shame users felt about their actions during gameplay. As a psychological state, absorption is driven by sustained full attention to a narrow set of stimuli to the point of losing awareness of everything else (Lavoie and Main 2019a). The participants were also asked to complete follow-up measures later in the day, which showed that the enhanced negative emotions resulting from the use of VR had a significant positive correlation with negative rumination, a maladaptive form of self-reflection characterized by repetitive and passive thought patterns focusing on the symptoms and causes related to the distressing event (Nolen-Hoeksema 1991). This is noteworthy, as the pretest findings suggested that the scenario used in this experiment was relatively neutral with regard to negative emotions elicited.

Given VR's ability to produce such powerful effects with relatively neutral stimuli, it is plausible that such effects may become even more pronounced in response to more stressful VR gaming experiences. Thus, our results provide preliminary evidence that, depending on the nature of the gameplay, VR use can cause some users to experience emotional harm and that firms producing VR video games ought to take steps to mitigate such harm in the design and marketing of their products.

\section{Literature review}

\subsection{Is VR harmful?}

The potential harm caused by VR is well established, with negative side effects having been reported since in the early 1990s (e.g., Sherman and Judkins 1992). Perhaps the most well-documented and prevalent negative consequence of VR is that it can cause users to experience vertigo, nausea, or dizziness (Jones 1996; Akiduki et al. 2003), also referred to as cybersickness or simulator sickness (e.g., Mittelstaedt et al. 2019). Fortunately, most cybersickness symptoms are mild and subside relatively quickly (Nichols and Patel 2002). More recently, research has explored and demonstrated other negative consequences related to $\mathrm{VR}$, including reduced cognitive performance (e.g., reaction times, Mittelstaedt et al. 2019; Szpak et al. 2019), physical fatigue (Smith and Burd 2019), eye fatigue (Cao et al. 2019), postural instability (Kennedy and Stanney 1996), and physical discomfort (Wibirama et al. 2019). Despite the abundance of evidence for potential negative consequences related to VR usage, these consequences have predominantly been related to negative physical and/or physiological outcomes. As such, this research expands the literature on the negative outcomes of VR usage by exploring its potential negative psychological/ emotional consequences.

Given the nascent level of understanding with regard to the emotional/psychological outcomes of VR gameplay, we attempted to gain further insight by interviewing various VR industry professionals. These interviews were conducted with the aim of establishing whether VR developers give consideration to potential negative consequences related to VR usage, and to gain unique insights regarding any potential side effects of VR usage, specifically those related to emotion and cognition. The sample consisted of a small group of professionals from five companies that create VR experiences. The participants possessed a wide range of experience within the industry, having held a variety of positions over their careers including developer, designer, producer, coder, creative director, writer, experience prototype creator, and project manager, among others. Each participant was asked two questions: (1) Are you aware of any negative consequences that users may experience from using VR and, if so, can you describe them? And (2) do you have any particular concerns for users beyond the established negative consequences and, if so, can you explain these concerns?

Notably, each participant indicated that they did have concerns related to user safety when creating virtual reality experiences. The most common concerns expressed by the participants related to the known physiological side effects of using VR technology, particularly motion sickness and the potential for users to suffer injuries while interacting with their surroundings during the virtual experience. Less common but still present were concerns related to emotional side effects that may persist after the VR experience has ended. Some comments exemplifying each concern are given in Table 1.

Even with this small sample, it is evident that developers are conscious of the physiological consequences of VR. However, the interviews also established that some participants wondered whether VR's ability to create highly realistic experiences may be powerful enough to leave longer lasting negative outcomes. This concern, combined with the participants' general lack of knowledge about these negative emotional/psychological consequences of VR use, provides the impetus for the present research. 
Table 1 Industry professional concerns

\begin{tabular}{|c|c|c|}
\hline Comment & Position & Type of danger \\
\hline "You need to be constantly wary of making your users sick" & VR designer & Physical \\
\hline $\begin{array}{l}\text { "I worry about experiences targeted at teens because the tech is designed for fully developed eyes and } \\
\text { optical systems" }\end{array}$ & UI/UX designer & Physical \\
\hline $\begin{array}{l}\text { "Experiences with lots of movement have resulted in injury when people accidently hit walls/objects in } \\
\text { their play space" }\end{array}$ & $\begin{array}{l}\text { VR company founder, } \\
\text { VR game designer }\end{array}$ & Physical \\
\hline "does the fear, or the after effects of it persist longer generating some type of PTSD style effects?" & VR designer, producer & Psychological \\
\hline "we are constantly worried about the potential psychological issues involved" & VR creative director & Psychological \\
\hline
\end{tabular}

\subsection{The potential side effects of playing video games}

There has been a long-standing debate in the literature about whether entertainment media such as video games are capable of causing some form of substantive psychological "harm." Due to the prevalence of violent content in such media, the majority of research in this area has focused on the relationship between violent content and aggression (Smith, Lachlan and Tamborini 2003; Collier et al. 2008). Findings have shown that exposure to violent video games has both short- and long-term effects on aggression, including increased prevalence and/or intensity of aggressive thoughts, affect, behavior, and delinquency (Anderson and Dill 2000; Anderson et al 2004).

In the short term, the effects of video game violence on aggression are partly driven by the in-game rewarding of violent behavior (Carnagey and Anderson 2005), competitiveness created by the video game (Anderson and Carnagey 2009), and arousal (Fleming and Rickwood 2001). In the long term, these effects tend to manifest in the form of desensitization to violence (Carnagey et al. 2007), changes in personality (Bartholow et al. 2005), and identification with the characters in the game (Funk and Buchman 1996; Schneider 2004). Significantly, desensitization to violence has also been associated with a decrease in empathy outside of the video game world (Funk et al 2003).

Video games can also have negative outcomes in the form of addiction (Chiu et al. 2004; Lemmens et al. 2009). In particular, video game addiction and extended playing time have been connected to decreased mental health, including lower life satisfaction and increased anxiety and depression (Mentzoni et al. 2011). Furthermore, excessive playing time can negatively impact mental health, as it can significantly reduce the quality and amount of sleep one gets (Krejci et al. 2011). Another concern in this domain is escapism, which is the maladaptive strategy of playing video games to escape from real-life problems (Kaczmarek and Drazkowski 2014). Becoming immersed in video games and entertainment media can be dangerous, as it can limit one's ability to keep track of and focus on things that are important in real life (Lavoie and King 2019; Lavoie and Main 2019b).

The relationship between violent content and aggression has also been demonstrated in VR, with findings having shown that exposure to violent VR can lead to elevated levels of aggression (Calvert and Tan 1994) and hostile thoughts (Tomborini, Eastin, Skalski, Lachlan, Fediuk and Brady 2004). However, while researchers have attempted to determine whether VR has greater potential to elicit higher levels of aggression compared to $2 \mathrm{D}$ video games, empirical support for this hypothesis is still lacking (Arriaga et al. 2008; Eastin and Griffiths 2006).

Although the above findings suggest that violent video game content and video game addiction pose significant dangers, there is a need for more research. For instance, reviews of the research on the negative effects of video games caution that the ability to establish causal relationships between video games and violent behavior is limited due to methodological concerns and inconsistencies in the data (Dill and Dill 1998). Moreover, meta-analysis findings suggest that the effect size of video game violence on aggression is smaller than that of TV violence (Sherry 2001), while other researchers have noted that a review of the literature raises concerns about publication bias (Ferguson 2007). Thus, there is a need for more empirical research on the potential negative effects of video game content, specifically whether the use of VR has a greater potential for negative emotional consequences (Eastin and Griffiths 2006; Ivory and Kalyanaraman 2007).

\subsection{Hypothesis development}

Our research contributes to the literature on the potential psychological harm of entertainment media by considering how the unique aspects of VR gameplay may produce negative emotional consequences. We seek to demonstrate that, unlike 2D gameplay and movies, VR possesses a unique ability to elicit negative emotions and rumination due to its ability to stimulate levels of emotional arousal that are almost identical to real life (Slater et al. 2006). We suggest that, relative to other technologies, virtual reality (VR) 
enhances absorption into gameplay, which intensifies negative emotion. Moreover, we suggest that the intensified emotional experiences resulting from VR lead to increased rumination and subsequent downstream negative consequences for users.

First, we explain why and how VR enhances absorption, referred to as a deep state of involvement characterized by feelings of temporal dissociation and focused immersion (Agarwal and Karahanna 2000). Absorption develops over time, after one has devoted full attention to a limited stimulus field for long enough that it becomes the totality of their awareness, causing them to lose track of time and self-awareness (Csikszenthimalyi and Lefevre 1989; Engeser and Rheinberg 2008; Lavoie and Main 2019a).

VR allows the user to experience an artificial environment firsthand through sensory stimuli (Lanier and Biocca 1992). Compared to other technologies, VR possesses several unique characteristics that foster absorption and that can enhance potential negative outcomes (Arriaga et al. 2008). Most notably, from a technological standpoint, VR features enhanced vivid imagery (i.e., breadth, depth) and interactivity (i.e., speed, range, mapping) (Steuer 1992). In addition to providing a surrounding visual environment and accommodating many sensory modalities, these technologies give VR the unique ability to transport people to mediated contexts that can be experienced as though they were real (Van Kerrebroeck et al. 2017). This unique psychological experience is called "presence," which refers to the feeling of being present in a particular computer-mediated environment as opposed to the current physical environment (Sheridan 1992).

It seems reasonable to posit that the degree to which a user becomes absorbed in a virtual environment will largely depend on the VR technology's ability to make the user feel as though they are in that environment rather than the physical environment (i.e., presence). Indeed, it has been suggested that presence is a critical factor in one's ability to experience absorption (Banos et al. 1999). The full visual field provided by VR eliminates all visual traces of the physical environment and fosters both the focused attention and temporal dissociation characteristic of absorption. VR's distinct elements of vividness and interactivity work in concert with this full visual field to engender differentiated (enhanced) degrees of presence in players, thus resulting in heightened levels of absorption (Murray et al. 2007).

We suggest that the increased absorption experienced in VR will in turn intensify emotions-including negative emotions-elicited from gameplay. For example, a player may experience varying degrees of anger, from being a little angry to very angry, as they become more deeply absorbed in the game. In fact, absorption has been suggested as the factor that determines VR's ability to induce physiological arousal (Macedonio et al. 2007). The power of absorption in VR is noteworthy, as VR experiences have been shown to elicit real physiological responses, including changes in heart rate (Dotsch and Wigboldus 2008), blood pressure, and cortisol (stress) levels (Bullinger et al. 2005).

Analysis of the factors that contribute to emotional intensity-for example, one's appraisal of a given context and their concerns about it (Sonnemans and Frijda 1995)—further supports the positive relationship between emotional intensity and absorption (Riva et al. 2007). As such, we hypothesize that absorption induced through VR gameplay will enhance one's appraisal of their context, as well as their concerns related to it. With regard to appraisals, the emergence and intensity of emotion will be based in part on how real the player perceives the situation to be, including their ability to interact with the scenario and the implications of their actions (Frijda 1988). In particular, situations that feel highly realistic will elicit a high degree of emotional intensity, whereas those that do not will only elicit a weak emotional response, if any at all (Ortony and Clore 1988). Since absorption has been suggested to be a mediating factor in determining the perceived realness of a VR experience (Banos et al. 1999), it follows that it would also be a primary contributor to such appraisals and the emotional intensity elicited by them.

It has been suggested that emotions arise and intensify only if an event is deemed to be relevant, as one's particular goals and interests largely determine the degree of importance (i.e., concern) assigned to various situations and behaviors. Thus, events that are deemed relevant and important tend to elicit more intense emotions (Sonnemans and Frijda 1995). Since absorption into a given event is partly driven by a high degree of interest and full involvement in that event (Csikszentmihalyi and LeFevre 1989), the emotions that are experienced during that event should be perceived as relevant and important. As a result, these emotions are more likely to be activated and intensified. The inherent importance and relevance of emotion in VR experiences is evidenced by the relatively strong level of empathy that users feel for the characters when they are absorbed in the experience (Shin 2018). Furthermore, findings have revealed a high degree of congruence between behavior in VR and behavior in real life (McCall et al. 2009). For example, the performance of participants in a VR simulation of Milgram's obedience experiments was almost identical to the performance of participants in the original studies (Slater et al. 2006). These findings suggest that, compared to $2 \mathrm{D}$ games, emotions take on greater relevance and importance in VR as a result of its ability to create highly realistic contexts, which in turn cause users to become fully interested and involved (i.e., absorbed). Therefore, VR's enhanced ability to facilitate absorption not only increases the likelihood of eliciting emotions among users, but it also increases the likelihood 
that these emotions will be felt more strongly than those experienced in $2 \mathrm{D}$ games.

In summary, we suggest that, relative to $2 \mathrm{D}$ technologies, VR will intensify any negative emotions experienced as a result of one's actions during gameplay. This relationship will be mediated by VR's ability to enhance absorption into gameplay, which will increase the importance of the gameplay and the subsequent intensity of emotions that are experienced, including negative emotions. The mediation model is formulated below as a formal hypothesis and presented graphically in Fig. 1.

H1 Relative to 2D technologies, VR will enhance absorption into an experience, which will mediate an increase in the intensity of negative emotions that result from one's actions during the VR experience.

We suggest that, in addition to their immediate consequences, enhanced negative emotions can lead to problematic downstream effects such as negative rumination, which is a maladaptive form of self-reflection consisting of repetitive thoughts focused on unpleasant stimuli (Nolen-Hoeksema et al. 2008). Negative rumination can be a powerful source of anxiety and depression (Nolen-Hoeksma 2000; Mor and Winquist 2002), as lingering negative emotions can lead to and be amplified by intrusive rumination (Taku et al. 2009). In extreme cases, negative rumination can result in conditions such as post-traumatic stress disorder (Yehuda 2002), as the intense emotions associated with the ruminated upon event are re-experienced and can become amplified with each iterated recollection (Sonnemans and Frijda 1995).

While violent video games (e.g., Fortnite, Grand Theft Auto) often require players to commit morally egregious acts, such as killing someone, the emotional/psychological consequences of such acts tend to be relatively minor due to relative lack of realness in 2D video games. Given VR's enhanced sense of realness, we suggest that it is critical that developers understand where to draw the line with VR experiences, and to understand the potential negative consequences that can result from such morally challenging content. Since we did not want to intentionally expose our participants to actual harm, this research sought to demonstrate that even VR situations causing relatively low amounts of stress can lead to negative rumination hours afterward.
H2 The intensity of negative emotion after the VR experience will have a significant positive correlation with negative rumination after the experience.

\subsection{Research studies}

Study 1 was designed to establish whether actual users of VR have experienced negative affective outcomes from using this technology. To this end, VR users were asked to answer a survey that was designed to capture their past experiences with VR. Although this methodology does not directly support our hypotheses, it provides a real-world retrospective examination of the issue. Given this, Study 2 was designed to provide direct support for Hypotheses 1 and 2 by having participants engage in an actual VR gameplay experience.

\subsection{Study 1: VR user self-reports of past VR experiences}

The goal of Study 1 was to provide partial support for Hypothesis 1 by obtaining initial evidence that VR products are capable of eliciting intense negative emotional experiences, depending on the nature of the gameplay. It is important to note that Study 1 did not specifically explore the negative outcomes of using VR; rather the focus was users' negative experiences within the VR world itself, for example, experiencing extreme levels of fear while playing a VR horror game. We employed a survey methodology with a larger group of gamers in order to gather information about their negative affective experiences with VR games. This approach was selected because it allowed us to obtain information from a larger number of people than would be possible with in-depth interviews, while still allowing for enough depth and description to convey the intensity of the experiences.

\subsection{Method}

Participants The survey was conducted using Amazon's MTurk and Crowdflower, which are both online crowdsourcing platforms. A total of 138 respondents were recruited across both platforms $\left(M_{\text {age }}=34.55,61.31 \%\right.$ male), with participants receiving nominal compensation for their time.

Fig. 1 VR mediation model




Design and procedure Participants were asked whether they had ever had an intense negative VR experience that persisted afterward (yes/no). If they said yes, we asked them what bothered them about the experience and to describe it.

\subsection{Results}

Of the 138 participants, $96(69.57 \%)$ had tried virtual reality. Of the 96 people who had tried VR, 34 (35.42\%) reported having had a strong negative affective experience that persisted after the VR experience had finished, with a large portion of these respondents reporting that the affect persisted for a relatively significant period. The open-ended survey responses were analyzed by looking for evidence of intense negative emotion. Some examples of the negative experiences described by the participants that demonstrate a heightened level of intensity are provided in Table 2.

The survey results suggest that, for many users, the realness of the VR experience intensifies negative emotions. As we theorized, the participants cited the realness of the VR experience and the attendant sense of presence as the key factors behind the intensification of negative emotions (i.e., fear, anxiety). Although the results of Study 1 do not provide direct support for our hypotheses, the number of participants who reported experiencing intense negative affect, along with their descriptions, provides preliminary support for our claim that virtual reality experiences can contribute to negative affect. Importantly, the results of Study 1 are based on user experiences with actual VR games/experiences that exist in the marketplace. In Study 2, we attempt to demonstrate VR's ability to elicit more powerful emotional experiences by having users play a game wherein they must negotiate difficult moral dilemmas, rather than simply dealing with the sort of "scary" stimuli (e.g., creatures jumping out) typically described by the participants in Study 1 .

\subsection{Study 2: virtual reality product trial}

Study 2 was designed to gain a deeper understanding of how users are affected by experiencing stressful or negative emotions in virtual reality. This study was designed to achieve two primary goals. First, it sought to support Hypothesis 1 by demonstrating that participants will become more absorbed in the VR experience (vs. the 2D experience on the laptop) and that their level of absorption in this experience mediates the strength of any negative emotions experienced by them. Second, it sought to support Hypothesis 2 by demonstrating the relationship between the strength of the participants' negative emotions and the amount of negative rumination that occurs following the experience. However, before Study 2 could be conducted, we needed to develop a scenario in VR that was capable of eliciting a moderate amount of negative emotion.

\subsubsection{Pretest}

We partnered with a local game developer to create a custom script and VR experience for use in this study. Given our concerns about the potential consequences of negative emotion resulting from VR use, we aimed to develop a scenario that would only induce a moderate amount of negative emotion. To this end, we brainstormed situations wherein the participant may be required to act in a way that might elicit negative emotions, but not be forced to do anything unconscionably bad (e.g., murder). Ultimately, we chose a bartending scenario because we wanted the participant to have to engage with a stranger who had done something wrong partly due to participant's actions. Specifically, the VR scenario situates the participant as a bartender who has overserved a customer; this customer then does something "bad," thus creating the potential for the participant to feel negative emotions due to their role in the customer's behavior. To determine a situation that would induce different degrees of negative emotional response, we first generated a series of outcome scenarios of varying severity wherein the overserved customer: assaulted and killed someone; assaulted their significant other; killed someone while texting and driving; assaulted a stranger; robbed a convenience store; crashed their car into a building causing damage; and stole a vehicle. We then ran a pretest to determine the strength of the negative emotions elicited by each of these outcomes in order to find a scenario that would elicit a moderately negative emotional response.

Participants in the pretest (42 MTurk workers, $M_{\text {age }}=34.81,64.3 \%$ male) were asked to rate how badly they would feel on a scale from 1(not upset at all) to 7 (very upset) if their decision to overserve someone had resulted in the above-described scenarios. The averages for each scenario were as follows: fought and killed someone (6.24); assaulted their significant other (6.12); killed someone while texting and driving (6.05); assaulted a stranger (5.86); robbed a convenience store (5.45); crashed their car into a building causing damage (5.21); and stole a vehicle (5.17). We selected "assaulted a stranger" for the VR gameplay script because we wanted a scenario that would be powerful enough to elicit negative emotions without risking harm to participants. In addition, we attempted to further protect the participants by making sure that the VR scenario did not require them to witness or take part in the act themselves. Thus, our study provides a conservative measure of the potential negative emotional consequences of VR. 


\subsubsection{Main study method}

Participants Forty-eight participants (aged 18-62, $M_{\text {age }}=24.60,54.2 \%$ male, $29.2 \% \mathrm{ESL}$ ) were recruited on the campus of a large Canadian University and were compensated $\$ 20$ for their participation in the study.

Design Participants were randomly assigned to one of the two groups. Those in the first group engaged with the pretested and developed virtual reality simulation using an HTC Vive head-mounted display; those in the second group engaged with the same scenario on a 15.4" MacBook Pro laptop, which had an Intel Core i7 processor, 16-GB memory, and a Radeon Pro $555 \times$ graphics card on a Mojave operating system. This created a 2-cell between-participants experimental design. Dependent measures related to negative emotions were collected using a follow-up questionnaire immediately after the gameplay experience.

Procedure The participants assigned to the laptop condition were taken to a table in a separate area that had been reserved. A research assistant explained how to use the Mac laptop buttons, the nature of the task, including how to navigate through the story, and the choices they could make. The participants were then given Apple in-ear headphones and were left to complete the scenario. Participants in the VR condition were given a 5-min tutorial by the VR developer on how to use the VR equipment, including the handset controllers. They were then given an opportunity to practice the tasks they would engage in during the scenario, including grabbing items and clicking on virtual buttons. Once the participants felt comfortable using the VR controls, the gameplay scenario was started under the supervision of the VR developer and the primary researcher.

All participants engaged in a story simulation in which they assumed the role of a bartender serving a customer drink. As the participants progressed through the experience, they engaged in a conversation with the customer by selecting between two to three responses to the customer's remarks. Eventually, the customer becomes intoxicated due to being overserved and leaves the bar. The participant is then shown a news article detailing how, after leaving the bar, the customer assaulted someone and put them in the hospital. The next day, the customer returns to the bar, while the police are looking for him. At this point, the participants must choose whether to let the customer go free, inform the police about the customer's whereabouts behind their back, or to inform customer that they are notifying the police of their whereabouts (see Appendix for the story description and characters). Following the gaming experience, we assessed our variables of interest through a questionnaire.

\subsection{Questionnaire}

In order to measure our mediator (absorption), we used the flow absorption subscale (Rheinberg et al. 2003; four items, $a=0.80$ ), which includes items such as "I lost track of time" and "I was completely absorbed in the experience." We also wanted to demonstrate that increased absorption mediated an increase in the strength of the negative emotions experienced by the participants. In order to assess negative emotion, we asked participants, "to what degree did you feel ashamed from what happened in the scenario?" $(1=$ not at all, $7=$ very much so). We chose to assess shame because it is a negative emotion that would be related to the VR gaming scenario. Furthermore, shame is a negative emotion that is activated when someone makes an internal attribution about a socially undesirable outcome (Tracy and Robbins 2004). As the bartender in the scenario, the participants may partially blame themselves for the assault due to overserving the customer, thus inducing shame.

Lastly, we wanted to demonstrate that the strength of the experienced negative emotion is positively correlated with negative rumination after the experience. In order to measure negative rumination, we sent all participants a link to a questionnaire four hours after the study. The questionnaire asked participants whether they had any negative thoughts about the experience since finishing the study (yes/no); if the participant answered "yes" to this question, they were further asked to estimate the number of negative thoughts they had and to describe the thoughts to the best of their ability. The questionnaire also included demographic measures and other measures that were of interest to the company we had partnered with to create the scenario. As such, these results are not discussed here.

\subsection{Results}

We ran an independent samples $t$ test between the two groups in order to determine whether the participants in the VR scenario had a greater level of absorption than their counterparts in the laptop condition. The test for homogeneity of variance across the two groups revealed no difference in variance $(F=0.606, p=0.440)$. The results of the $t$ test revealed that the two groups differed in level of absorption, with those in the VR condition being more absorbed $\left(M_{\mathrm{VR}}=4.64, S . D .=1.20\right)$ than those in the computer condition $\left(M_{\text {COMPUTER }}=3.88, S . D .=1.41, t(46)=2.05\right.$, $p=0.047$ ). We also ran the same analysis on how ashamed participants felt after the VR experience. Once again, the test for homogeneity of variance across the two groups revealed no difference in variance $(F=0.003, p=0.960)$, while the independent sample $t$ test showed that those in the VR condition reported feeling more shame $\left(M_{\mathrm{VR}}=3.62, S . D .=1.68\right)$ than those in the computer condition $\left(\mathrm{M}_{\text {COMPUTER }}=2.59\right.$, $S . D .=1.62, t(46)=2.14, p=0.038)$. 
Based on Hypothesis 1, the participants' feelings of shame should be mediated by their degree of absorption into the VR scenario. To examine this relationship, we ran Model 4 of the SPSS Process Macro (Hayes 2013). The results of this analysis showed that absorption mediates the effect of VR on feelings of shame, as the $95 \%$ confidence interval of the indirect effect did not contain zero $[\beta=0.3084$, S.E. $=0.2018,95 \%$ C.I. $=0.0262,0.8865]$. When considered alongside the positive path between VR and absorption $[\beta=0.7692$, S.E. $=0.3760,95 \%$ C.I. $=0.0124,1.5261]$, the positive path between absorption and feelings of shame $[\beta=0.4009$, S.E. $=0.1800,95 \%$ C.I. $=0.0383,0.7635]$, and the lack of a significant direct relationship between VR and feelings of shame when absorption is included in the model $[\beta=0.7161$, S.E. $=0.4795,95 \%$ C.I. $=-0.2497,1.6819]$, this result supports the hypothesis that absorption accounts for why participants in the VR condition experienced stronger negative emotions as a result of their actions than those in the laptop condition (Fig. 2).

Lastly, we wanted to demonstrate that the increased levels of shame among participants in the VR condition had a significant positive relationship with rumination following the experience. To this end, we ran a bivariate correlation based on the 30 participants $(62.5 \%)$ who answered the follow-up questions. As expected, the results revealed a significant positive correlation $(r(30)=0.383, p=0.038)$ between shame and negative rumination following the VR experience. We also conducted a binary logistic regression with shame as the independent variable predicting whether participants ruminated (yes/no) about the experience. Once again, the results indicated that feelings of shame increased the likelihood of negative rumination $($ Wald $=3.12, \beta=1.12$, S.E. $=0.632$, $p=0.077$ ). To validate our findings, we assessed the normality of the interval data (shame), which revealed acceptable levels of skewness $(=0.452$, Std. Error $=0.343$ and Kurtosis $=-0.672$, S.E. $=0.674$ ) (Hair et al. 2017). Together, these findings provide further insight into the concerns that emerged during our interviews with industry professionals, and they also provide support for our survey results by empirically demonstrating that the use of VR technology can in fact have negative emotional consequences. We discuss the contributions and implications of these findings below.

\section{General discussion}

Although the immersive nature of VR enhances experiences in many contexts, our research highlights the need to understand the potential negative emotional consequences that can result from the use of this technology. The present research contributes to the literature by demonstrating an ethical concern related to VR use, such that relative to 2D video games, VR games are capable of intensifying negative emotions elicited during gameplay and that these emotions persist beyond the gameplay experience. As the results of Study 2 demonstrate, absorption into the gaming experience mediates the intensification of negative emotions experienced during VR gameplay. These findings are further supported by the results of our survey of VR users, which also showed that the use of this technology can lead to negative emotional outcomes.

The studies presented herein serve as a foundation for future research into the negative consequences of VR use and as a call for raised awareness in VR industry practices. The primary takeaway from this research is twofold: First, it is critically important to understand the various harms that may be caused by the wide range of VR situations that users may be exposed to; and, second, it is essential that developers take steps to manage the potential for such harm. The interviews conducted with industry professionals in Study 1 highlighted a desire for and lack of knowledge about the psychological consequences of VR. Despite their concern for the well-being of VR users, VR developers continue to

Fig. 2 VR mediation findings

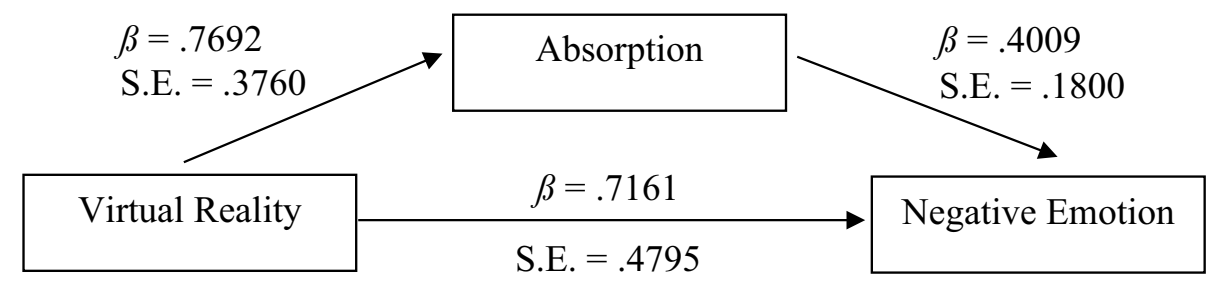

Table 2 Study 1 comments

\begin{tabular}{l}
\hline Comment \\
"it was some horror game I was playing and something scared the crap out of me and I ended up freaking out, falling over and \\
throwing up. It had me fearful to use the equipment for about a week and I got sick even just thinking about it" \\
"I was playing a horror video game in VR and became very stressed out and scared while playing the game. I had to take the \\
headset off and just stop playing. I had nightmares that night" \\
"I tried a scary game in my headset. It had a lot of tension and was extremely realistic. It stressed me out and made me want to Participant \#2 \\
avoid scary games"
\end{tabular}


operate without fully understanding the implications of their products, thereby limiting their ability to take steps to mitigate any negative outcomes.

With respect to harm management, there are a number of potentially effective avenues that could be explored. From a public policy perspective, a VR-specific rating system could be implemented in order to warn users of a game's potential to cause harm. This approach has already been implemented for other video games due to concerns over children's exposure to inappropriate stimuli, with game content currently being monitored by the Entertainment Software Rating Board "ESRB" (Stroud and Chernin 2008). Under this policy, the ESRB provides age-based suggestions based on the amount of violence, sexual content, and profanity within a given game through designations such as "E10+" (10 and older) and "AO" (adults only). Our results suggest that VR use can have unique consequences and that both academics, VR developers, and policy makers should establish which types of scenarios should be limited in VR and what content is appropriate for various age groups.

Organizations, including those that develop VR content, are held to ethical standards based on their responsibilities to stakeholders, which include the well-being of those who use their products, their environmental impact, and their impact on society as a whole (Carroll 1979). As such, organizations are increasingly expected to take responsibility for more social and environmental issues relevant to their operations through their policies and actions (Young 2008). Lindorf et al. (2012) suggest that social responsibility entails the appropriate regulation and governance of a firm' activities and that social responsibility should be integrated within a firm's strategy. Given the ethical concerns related to VR content highlighted by our findings, we suggest that VR firms have a duty to ensure the safety of the people who use their products. Following theory related to corporate social responsibility, we suggest that development and research into new VR products should carefully consider the negative emotional outcomes discussed in this research. Ultimately, we hope that this research sparks future conversations about the potential psychological/emotional consequences of virtual reality and how these potentially adverse effects can be mitigated in order to protect VR users.

\section{Limitations and future research}

One key limitation of this research is that we only experimentally evaluated one potentially harmful situation. As such, future research should be conducted to demonstrate other types of stimuli/situations that may potentially be harmful to VR users. In addition, we considered a low to moderately stressful situation that does not require the user to commit a crime or a harmful act. However, other video games or VR experiences are likely to contain scenarios that require users to perform such actions, for instance, defending themselves from a robbery or committing the sort of violent acts that are common in a game like Grand Theft Auto. Given VR's high level of realism, video games in this medium could potentially expose players to situations that take a long time to recover from emotionally and can have other downstream psychological effects, for example the death of a character who is important to them or some other traumatic event.

On the other hand, it is important to note that some content may not elicit an increased amount of negative emotion in VR. We used a scenario in which the participant's behaviors elicited stronger negative emotion in VR. However, pictures/symbols such as a road sign that suggests danger can elicit negative emotion in 2D which may not increase in strength in VR. Furthermore, since the focus of our research was limited to shame, future research should explore other negative VR-related emotional outcomes such as sadness, depression, and anxiety.

Our research focused exclusively on the emotional reactions of adults, but it is very likely that younger players, including children, will experience more extreme emotional reactions (Drolet et al. 2007). Therefore, research should explore which demographics are most susceptible to the negative effects of VR. For instance, it seems plausible that VR users who are higher in moral identity might be more negatively affected by their choices during gameplay, as moral identity is a chronic part of one's self-concept that is represented by a set of moral traits, such as being caring or empathetic (Aquino and Reed II 2002). As we demonstrate in Study 2, the degree to which someone becomes "absorbed" in a VR scenario will influence the intensity of their negative emotional outcomes. Thus, it would be interesting to explore individual differences in levels of absorption, for example openness to experience, which is characterized by a drive to examine and experience seeking (McCrae and John 1992).

It will also be important for future research to gather longitudinal data, as this will enable a more robust to understand the VR's long-term effects. Our data were limited in the sense that we followed up with participants later the same day; as such, future research could analyze a more broad time frame in order to understand how long it takes for such effects to dissipate, or whether they actually get worse over time. Indeed, it is possible that negative rumination or affect may strengthen over time or with repeated game play, or that the emotionally charged VR experiences may interact with other events in a user's life to produce negative emotional consequences. Relatedly, there are individual difference variables, such as age or personality factors, that will influence the amount of time it takes for the emotions to dissipate (Ridgway et al. 1990; Ahn et al. 2016). Another possibility is that VR users will become desensitized to the stimuli in VR and will have less negative emotional experiences over time.

While our research demonstrates one potential negative consequence of VR usage, it is important to note that VR may also have many positive consequences. Similar to our findings 
related to VR's ability to enhance negative emotions and cognitions, studies have shown that VR can also enhance positive emotion and cognitions. For example, VR can be used to help treat disorders related to stress and anxiety (Aiken and Barry 2015; Serino et al. 2014) through cognitive training programs like mindfulness (Wiederhold and Wiederhold 2008; Chandsarisi et al. 2020). VR can also elicit rare positive emotions like awe (Chirico et al. 2017, 2018), which can in turn have several positive consequences, including an increased sense of wellness and life satisfaction (Keltner and Haidt 2003). Future research should explore how to create content in VR that fosters awe and other positive consequences (Quesnel and Rieke 2018), while also mitigating the negative consequences.

\section{Conclusion}

Our research provides initial support for the notion that VR content can elicit negative emotional outcomes for its users. Relative to 2D gameplay, VR facilitates a greater level of absorption among users, which in turn intensifies any negative emotions that may be experienced during gameplay. Significantly, this intense emotional experience subsequently leads to negative rumination about the experience after it has ended. The findings of this research are important given the literature's emphasis on the positive aspects of VR and the general lack of understanding regarding VR's negative effects. While the physiological effects of VR (e.g., nausea, "cybersickness") have been well established and are being actively mitigated, the emotional consequences are not. We suggest that policy makers and VR developers should take action to understand the emotional dangers of VR in order to protect consumers (Collier et al. 2008). In addition, we also suggest that more research be conducted to understand the potential severity of the negative emotional harm that can result from VR usage, as such research will be highly useful for devising a proper regulatory framework for this technology. For example, research should explore the breadth of decisions/situations in VR that can elicit strong negative emotions. While this research provides a conservative demonstration of VR's potential to cause harm, future research could explore whether VR situations that require the user to engage in morally egregious behavior (e.g., murder) intensify negative emotions even more. Longitudinal research designs will also be critical in determining whether the negative effects of VR persist longer than the one-day period explored in this research.

Open Access This article is licensed under a Creative Commons Attribution 4.0 International License, which permits use, sharing, adaptation, distribution and reproduction in any medium or format, as long as you give appropriate credit to the original author(s) and the source, provide a link to the Creative Commons licence, and indicate if changes were made. The images or other third party material in this article are included in the article's Creative Commons licence, unless indicated otherwise in a credit line to the material. If material is not included in the article's Creative Commons licence and your intended use is not permitted by statutory regulation or exceeds the permitted use, you will need to obtain permission directly from the copyright holder. To view a copy of this licence, visit http://creativecommons.org/licenses/by/4.0/.

\section{Appendix}

Customer in scenario.

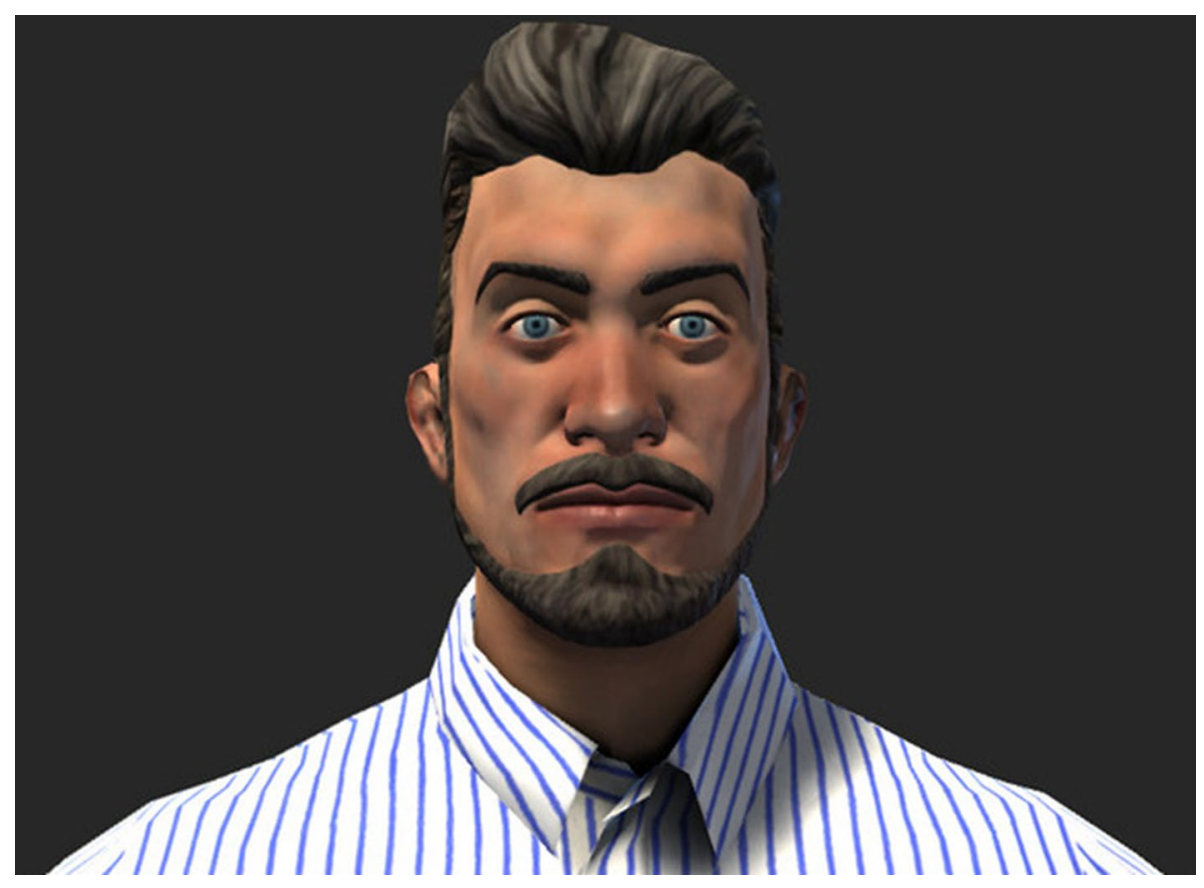


Outline of the VR Scenario.

Participants engage in a conversation with a customer at the bar that they are a bartender at. They go through a series of questions with them in which they choose what to ask him. The scenario goes as follows:

\section{Start}

You are a bartender. The bar is quiet, it's getting late on a slow night.

A grumpy looking male, aged around 20-25 straddles up to the bar. He looks like he's having a bad day. He already looks like he's had a few drinks.

Choice- you ask if you can help him or you pour him a drink without saying anything.

The man thanks you and says he's had a tough day and asks for a drink, so you serve him.

Choice- ask about it directly or show support but don't ask anything.

He tells you a bit about his day. His car is running funny, he's scared of being fired... he says it's becoming the status quo.

Choice- you ask about the car, ask about his job, or agree with him.

He tells you about his car. Due to life circumstances he cannot afford it to run properly. His car has been overworked by taking his mom for cancer treatments. He tells you what he does and how much he hates it. He needs to keep the car to coordinate taking his daughter because he cannot afford childcare. He sips his drink in silence and then asks for another drink.

Choice- You pour one or you decline.

He's had a tough day. He goes on a bit about his girlfriend and the problems with her.

Choice- you ask about his mom or you ask about his daughter.

He talks a bit about his family he asks for more alcohol.

Choice- you give him the bottle or you give him just one drink.

He finishes it quickly and asks for more. You pour another. He talks more about his life and how he ended up doing shift work due to his girlfriend's school, his mother's cancer and juggling childcare for his daughter. He doesn't get much time off or alone, his life is all about taking care of others. He feels like his own health is deteriorating due to this and he hasn't gotten a good night sleep in a while. He thanks you for being an ear to listen and walks out of the bar drunk.

\section{End of day 1}

\section{Start of day 2}

You see a news report from the police about a crime committed (assault) and Crime Stoppers is looking for the suspect. They describe the same man that was in your bar.

Later that evening the same man walks back into your bar. He looks worse for wear. He is wearing the same clothes as yesterday and matches the police description. He asks for a drink.

Choice- you ask him about his day or you pour him a drink.

$\mathrm{He}$ is vague, he starts explaining another tough day but says at least he can have some alone time right now. You mention the news report as just happening around the same time as he left and ask whether it was him. He says he keeps having bad days but he denies that was him. He asks why you think it might be him. You say that he is wearing the same clothes, that the description seems like him and it matches the time and place.

He replies by saying, I guess I have the same clothes as the report, but lots of guys wear the same clothes. You press for information, you tell him you care. He says yeah, he matches the description, but so do lots of guys-a lot of guys would match that description. He asks for a drink.

You pour him one. After a while he sighs and confesses that it is him. He's the one the police are looking for BUT - he has a good reason as to why. He explains the situation, admits to the crime and tries to say that his emotions got the best of him and that he was too drunk. You tell him that he messed up, but you are sympathetic.

He agrees, he isn't proud of it. But he can't go to jail. He makes a compelling argument as to why that would be worse for everyone and why he wishes he could just slip back into his life. His mother, girlfriend and daughter depend on him for everything. If he is gone his mother won't be able to make it to her treatments, his girlfriend will have to go to school (to go back into the workforce) and his daughter will have to go to more childcare (which is too expensive for them). And it was just a simple misunderstanding, he never meant for this to happen.

CHOICE 1: You can report him to the authorities while he is in your bar so he can be arrested. He is very hurt after just pouring his heart out to you.

CHOICE 2: You can tell him you feel for him and that he should lay low for a while. He thanks you for being a good friend.

CHOICE 3: You tell him that you feel for him (to his face), but also call the cops (behind his back) to give them your information on the crime. 


\section{References}

Agarwal R, Karahanna E (2000). Time flies when you're having fun: cognitive absorption and beliefs about information technology usage. MIS Q 665-694.

Ahn H, Sung Y, Drumwright ME (2016) Consumer emotional intelligence and its effects on responses to transgressions. Market Lett 27(2):223-233

Aiken MP, Berry MJ (2015) Posttraumatic stress disorder: possibilities for olfaction and virtual reality exposure therapy. Virtual Real 19(2):95-109

Akiduki H, Nishiike S, Watanabe H, Matsuoka K, Kubo T, Takeda N (2003) Visual-vestibular conflict induced by virtual reality in humans. Neurosci Lett 340(3):197-200

Anderson CA, Carnagey NL (2009) Causal effects of violent sports video games on aggression: Is it competitiveness or violent content?. J Exp Soc Psychol 45(4):731-739

Anderson CA, Dill KE (2000) Video games and aggressive thoughts, feelings, and behavior in the laboratory and in life. $\mathrm{J}$ personalsoc psychol 78(4):772

Anderson CA, Carnagey NL, Flanagan M, Benjamin Jr, AJ, Eubanks J, Valentine JC (2004) Violent video games: Specific effects of violent content on aggressive thoughts and behavior, Vol. 36 of Advances in Experimental Social Psychology

Arriaga P, Esteves F, Carneiro P, Monteiro MB (2008) Are the effects of Unreal violent video games pronounced when playing with a virtual reality system?. Aggress Behav 34(5):521-538

Aquino K, Reed A II (2002) The self-importance of moral identity. J Pers Soc Psychol 83(6):1423-1440

Banos R, Botella C, Garcia-Palacios A, Villa H, Perpiñá C, Gallardo M (1999) Psychological variables and reality judgment in virtual environments: the roles of absorption and dissociation. CyberPsychol Behav 2(2):143-148

Barfield W, Hendrix C (1995) The effect of update rate on the sense of presence within virtual environments. Virtual Real 1(1):3-15

Bartholow BD, Sestir MA, Davis EB (2005) Correlates and consequences of exposure to video game violence: Hostile personality, empathy, and aggressive behavior. Pers Soc Psychol Bull 31(11:1573-1586

Bullinger AH, Hemmeter UM, Stefani O, Angehrn I, Mueller-Spahn F, Bekiaris E, Mager R (2005) Stimulation of cortisol during mental task performance in a provocative virtual environment. Appl Psychophysiol Biofeedback 30(3):205-216

Calvert SL, Tan SL (1994) Impact of virtual reality on young adults' physiological arousal and aggressive thoughts: Interaction versus observation. J appl dev psychol 15(1):125-139

Cardoş RA, David OA, David DO (2017) Virtual reality exposure therapy in flight anxiety: a quantitative meta-analysis. Comput Hum Behav 72:371-380

Carnagey NL, Anderson CA (2005) The effects of reward and punishment in violent video games on aggressive affect, cognition, and behavior. Psychol sci 16(11):882-889

Carroll AB (1979) A three-dimensional conceptual model of corporate performance. Acad Manag Rev 4(4):497-505

Cao S, Nandakumar K, Babu R, Thompson B (2019). Game play in virtual reality driving simulation involving head-mounted display and comparison to desktop display. Virtual Real 1-11

Carnagey NL, Anderson CA, Bushman BJ (2007) The effect of video game violence on physiological desensitization to real-life violence. J Exp Soc Psychol 43(3):489-496

Chandrasiri A, Collett J, Fassbender E, De Foe A (2019). A virtual reality approach to mindfulness skills training. Virtual Real 1-7

Chirico A, Cipresso P, Yaden DB, Biassoni F, Riva G, Gaggioli A (2017) Effectiveness of immersive videos in inducing awe: an experimental study. Sci Rep 7(1):1-11
Chirico A, Ferrise F, Cordella L, Gaggioli A (2018) Designing awe in virtual reality: An experimental study. Front Psychol 8:2351

Chiu SI, Lee JZ, Huang DH (2004) Video game addiction in children and teenagers in Taiwan. CyberPsychol Behav 7(5):571-581

Collier JE, Liddell P Jr, Liddell GJ (2008) Exposure of violent video games to children and public policy implications. J Public Policy Market 27(1):107-112

Csikszentmihalyi M, LeFevre J (1989) Optimal experience in work and leisure. J Pers Soc Psychol 56(5):815

De Gauquier L, Brengman M, Willems K, Van Kerrebroeck H (2018). Leveraging advertising to a higher dimension: experimental research on the impact of virtual reality on brand personality impressions. Virtual Real 1-19

Dill KE, Dill JC (1998) Video game violence: A review of the empirical literature. Aggress Violent Beh 3(4):407-428

Dotsch R, Wigboldus DH (2008) Virtual prejudice. J Exp Soc Psychol 44(4):1194-1198

Drolet A, Williams P, Lau-Gesk L (2007) Age-related differences in responses to affective vs. rational ads for hedonic vs. utilitarian products. Market Lett 18(4):211-221

Engeser S, Rheinberg F (2008) Flow, moderators of challenge-skillbalance and performance. Mot Emot 32:158-172

Eastin MS, Griffiths RP (2006) Beyond the shooter game: Examining presence and hostile outcomes among male game players. Commun Res 33(6):448-466

Ferguson CJ (2007) Evidence for publication bias in video game violence effects literature: a meta-analytic review. Aggress Violent Beh 12(4):470-482

Fleming MJ, Rick Wood DJ (2001) Effects of violent versus nonviolent video games on children's arousal, aggressive mood, and positive mood. J Appl Soc Psychol 31(10):2047-2071

Funk JB, Buchman DD (1996) Playing violent video and computer games and adolescent self-concept. J commun 46(2):19-32

Funk JB, Buchman DD, Jenks J, Bechtoldt, H (2003) Playing violent video games, desensitization, and moral evaluation in children. J Appl Dev Psychol 24(4):413-436

Frijda NH (1988) The laws of emotion. Am Psychol 43(5):349

Hayes AF (2013) Introduction to mediation, moderation, and conditional process analysis: a regression-based approach. Guilford Press, New York

Hair JF, Hult GTM, Ringle CM, Sarstedt M (2017) A primer on partial least squares structural equation modeling (PLS-SEM), 2nd edn. Sage, Thousand Oaks, CA

Ivory JD, Kalyanaraman S (2007) The effects of technological advancement and violent content in video games on players' feelings of presence, involvement, physiological arousal, and aggression. J Commun 57(3):532-555

Jones H (1996) Virtual reality: Panacea or pandora's box? Virtual Real 2(1):147-154

Kaczmarek LD, Drążkowski D (2014) MMORPG escapism predicts decreased well-being: examination of gaming time, game realism beliefs, and online social support for offline problems. Cyberpsychol Behav Soc Netw 17(5):298-302

Keltner D, Haidt J (2003) Approaching awe, a moral, spiritual, and aesthetic emotion. Cogn Emot 17:297-314

Kennedy RS, Stanney KM (1996) Postural instability induced by virtual reality exposure: development of a certification protocol. Int J Hum Comput Interact 8(1):25-47

Krejci M, Wada K, Nakade M, Takeuchi H, Noji T, Harada T (2011) Effects of video game playing on the circadian typology and mental health of young Czech and Japanese children. Psychology 2(07):674

Lanier J, Biocca F (1992) An insider's view of the future of virtual reality. J Commun 42(4):150-172

Lau KW, Lee PY (2018). Shopping in virtual reality: a study on consumers' shopping experience in a stereoscopic virtual reality. Virtual Real 1-14 
Lavoie R, King C (2019). The virtual takeover: the influence of virtual reality on consumption. Canadian Journal of Administrative Sciences, August (Early View).

Lavoie R, Main K (2019) Consumer microflow experiences. Psychol Market 36:1133-1142

Lavoie R, Main KJ (2019b). When losing money and time feels good: The paradoxical role of flow in gambling. J Gambl Issues 41

Lemmens JS, Valkenburg PM, Peter J (2009) Development and validation of a game addiction scale for adolescents. Media Psychol 12(1):77-95

Lindorff M, Jonson EP, McGuire L (2012) Strategic corporate social responsibility in controversial industry sectors: the social value of harm minimisation. J Bus Ethics 110(4):457-467

Macedonio M, Parsons T, Digiuseppe R, Weiderhold B, Rizzo A (2007) Immersiveness and physiological arousal within panoramic video-based virtual reality. Cyberpsychol Behav 10(4):508-515

McCall C, Blascovich J, Young A, Persky S (2009) Proxemic behaviors as predictors of aggression towards Black (but not White) males in an immersive virtual environment. Soc Influ 4(2):138-154

McCrae R, John O (1992) An introduction to the five-factor model and its applications. J Pers 60(2):175-215

Mentzoni RA, Brunborg GS, Molde H, Myrseth H, Skouverøe KJM, Hetland J, Pallesen S (2011) Problematic video game use: estimated prevalence and associations with mental and physical health. Cyberpsychol Behav Soc Netw 14(10):591-596

Mittelstaedt JM, Wacker J, Stelling D (2019) VR aftereffect and the relation of cybersickness and cognitive performance. Virtual Real 23(2): 143-154

Mor N, Winquist J (2002) Self-focused attention and negative affect: A meta-analysis. Psychol Bull 128:638-662

Murray CD, Fox J, Pettifer S (2007) Absorption, dissociation, locus of control and presence in virtual reality. Comput Hum Behav 23(3):1347-1354

Nichols S, Patel H (2002) Health and safety implications of virtual reality: a review of empirical evidence. Appl Ergon 33(3):251-271

Nolen-Hoeksema S (1991) Responses to depression and their effects on the duration of depressive episodes. J Abnorm Psychol 100:569-582

Nolen-Hoeksema S (2000) The role of rumination in depressive disorders and mixed anxiety/depressive symptoms. J Abnorm Psychol 109:504-511

Nolen-Hoeksema S, Wisco BE, Lyubomirsky S (2008) Rethinking rumination. Perspect Psychol Sci 3(5):400-424

Ortony A, Clore GL (1988). A. collins (1988). The cognitive structure of emotions.

Plante TG, Aldridge A, Bogden R, Hanelin C (2003) Might virtual reality promote the mood benefits of exercise? Comput Hum Behav 19(4):495-509

Quesnel D, Riecke BE (2018) Are you awed yet? How virtual reality gives us awe and goose bumps. Front Psychol 9:2158

Riva G, Mantovani F, Capideville CS, Preziosa A, Morganti F, Villani D, Alcañiz M (2007) Affective interactions using virtual reality: the link between presence and emotions. CyberPsychol \& Behav 10(1):45-56

Regan C (1995) An investigation into nausea and other side-effects of head-coupled immersive virtual reality. Virtual Real 1(1):17-31

Rheinberg F, Vollmeyer R, Engeser S (2003). Die Erfassung des FlowErlebens. [The assessment of flow experience]. In: tiensmeierPelster J, Rheinberg F (eds) Diagnosis of motivation and selfconcept, pp 261-279

Ridgway NM, Dawson SA, Bloch PH (1990) Pleasure and arousal in the marketplace: interpersonal differences in approach-avoidance responses. Market Lett 1(2):139-147

Schneider EF, Lang A, Shin M, Bradley SD (2004) Death with a story: How story impacts emotional, motivational, and physiological responses to first-person shooter video games. Hum Commun Res 30(3):361-375

Sen S, Bhattacharya CB (2001) Does doing good always lead to doing better? Consumer reactions to corporate social responsibility. J Mark Res 38(2):225-243

Seth A, Vance JM, Oliver JH (2011) Virtual reality for assembly methods prototyping: a review. Virtual Real 15(1):5-20

Serino S, Triberti S, Villani D, Cipresso P, Gaggioli A, Riva G (2014) Toward a validation of cyber-interventions for stress disorders based on stress inoculation training: a systematic review. Virtual Real 18(1):73-87

Sheridan TB (1992) Musings on telepresence and virtual presence. Presence Teleoper Virtual Environ 1(1):120-126

Sherman B, Judkins P (1992) Glimpses of heaven, visions of hell: virtual reality and its implications. Hodder \& Stoughton, London

Shin D (2018) Empathy and embodied experience in virtual environment: To what extent can virtual reality stimulate empathy and embodied experience?. Comput Hum Behav 78:64-73

Slater M, Antley A, Davison A, Swapp D, Guger C, Barker C, SanchezVives MV (2006) A virtual reprise of the Stanley Milgram obedience experiments. PLoS ONE 1(1):e39

Smith SP, Burd EL (2019) Response activation and inhibition after exposure to virtual reality. Array 3:100010

Smith SL, Lachl KL, Tamborini R (2003) Popular video games: Quantifying the presentation of violence and its context. J Broadcast \& Electron Media 47(1):58-76

Sonnemans J, Frijda NH (1995) The determinants of subjective emotional intensity. Cogn Emot 9(5):483-506

Steuer J (1992) Defining virtual reality: Dimensions determining telepresence. J Commun 42(4):73-93

Stroud NJ, Chernin A (2008) Video games and the esrb: an evaluation of parental beliefs about the rating system. J Child Media 2(1): $1-18$

Szpak A, Michalski SC, Saredakis D, Chen CS, Loetscher T (2019) Beyond feeling sick: the visual and cognitive aftereffects of virtual reality. IEEE Access 7:130883-130892

Taku K, Cann A, Tedeschi RG, Calhoun LG (2009) Intrusive versus deliberate rumination in posttraumatic growth across US and Japanese samples. Anxiety Stress Coping 22(2):129-136

Tamborini R, Eastin MS, Skalski P, Lachlan K (2004) Violent virtual video games and hostile thoughts. J Broad \& Elec Media 48:335

Tellegen A, Atkinson G (1974) Openness to absorbing and self-altering experiences (" absorption"), a trait related to hypnotic susceptibility. J Abnorm Psychol 83(3):268

Tracy JL, Robbins RW (2004) Putting the self into self-conscious emotions: a theoretical model. Psychol Inq 15(2):103-125

Van Kerrebroeck H, Brengman M, Willems K (2017) When brands come to life: experimental research on the vividness effect of Virtual Reality in transformational marketing communications. Virtual Real 21(4):177-191

Wibirama S, Santosa PI, Widyarani P, Brilianto N, Hafidh W (2019). Physical discomfort and eye movements during arbitrary and optical flow-like motions in stereo 3D contents. Virtual Real pp 1-13

Wiederhold BK, Wiederhold MD (2008) Virtual reality with fMRI: a breakthrough cognitive treatment tool. Virtual Real 12(4):259-267

Yehuda R (2002) Post-traumatic stress disorder. N Engl J Med 346(2):108-114

Young IM (2008) Responsibility and global justice: a social connection model. In: Scherer AG, Palazzo G (eds) Handbook of research on global corporate citizenship. Edward Elgar, Cheltenham, pp $137-165$

Publisher's Note Springer Nature remains neutral with regard to jurisdictional claims in published maps and institutional affiliations. 